\title{
PRODUÇÃO E ATIVAÇÃO DO CARVÃO VEGETAL DE TRÊS ESPÉCIES FLORESTAIS
}

\author{
Enoque Leda de Arruda ${ }^{1}$, Azarias Machado de Andrade ${ }^{1}$, Ananias Francisco Dias Júnior ${ }^{2 *}$ \\ ${ }^{1}$ Universidade Federal Rural do Rio de Janeiro, Departamento de Produtos Florestais, Seropédica, Rio de Janeiro, Brasil - \\ enoqueufrrj@bol.com.br; azarias@ufrrj.br \\ ${ }^{2 *}$ Universidade de São Paulo, Escola Superior de Agricultura "Luiz de Queiroz", Programa de Pós-Graduação em Recursos Florestais, \\ Piracicaba, São Paulo, Brasil - ananiasjr@usp.br
}

Recebido para publicação: 21/07/2017 - Aceito para publicação: 24/08/2017

\begin{abstract}
Resumo
Este estudo teve por objetivo analisar as variáveis da produção do carvão vegetal das madeiras de Acacia mangium, Pseudosamanea guachapelle e Eucalyptus grandis e analisar a capacidade de adsorção de pigmentos pelos carvões produzidos e ativados com vapor d'água superaquecido. Para isso, as amostras das madeiras foram carbonizadas sob as temperaturas de 400,500 e $600{ }^{\circ} \mathrm{C}$ numa velocidade de aquecimento de $1,67{ }^{\circ} \mathrm{C} \min ^{-1}$ e tempo total de carbonização de 4, 5 e 6 horas, respectivamente. Após a carbonização, determinaram-se os rendimentos gravimétricos em carvão, líquido pirolenhoso, gases não condensáveis e realizou-se a análise imediata dos carvões. Os carvões foram ativados sob a ação de vapor d'água superaquecido e testados em relação à adsorção de pigmentos coloridos dissolvidos em água. Para as três espécies analisadas, as menores temperaturas de carbonização proporcionaram os maiores rendimentos em carvão vegetal. As maiores temperaturas de carbonização resultaram nos menores teores de materiais voláteis e maiores teores de carbono fixo nos carvões. A ativação com vapor d'água superaquecido influenciou positivamente a adsorção de pigmentos do carvão de $P$. guachapelle produzido a $400{ }^{\circ} \mathrm{C}$ e dos carvões de $A$. mangium e E. grandis produzidos a $500^{\circ} \mathrm{C}$. A madeira de $P$. guachapelle carbonizada à $400{ }^{\circ} \mathrm{C}$ se destacou em relação às duas outras espécies florestais analisadas.

Palavras-chave: Vapor d'água superaquecido; adsorção de pigmentos em suspensão; carvão ativado.
\end{abstract}

\begin{abstract}
Production and activation of charcoal of three forest species. The objective of this study was to analyze the charcoal production variables of Acacia mangium, Pseudosamanea guachapelle and Eucalyptus grandis wood and to analyze the adsorption of pigments by the activated carbon with activated water vapor. The wood samples were carbonized at temperatures of 400,500 and $600{ }^{\circ} \mathrm{C}$, heating rate of $1.67{ }^{\circ} \mathrm{C} \mathrm{min}{ }^{-1}$ and total carbonization time of 4,5 and 6 hours, respectively. After the carbonization process, the gravimetric yields were determined in charcoal, pyroligneous liquid, non-condensable gases and the immediate analysis of the charcoal was carried out. The charcoal were activated with heated water vapor and tested for adsorption capacities of colored pigments dissolved in water. For the three species analyzed, the lower carbonization temperatures resulted in higher yields of charcoal. The higher carbonization temperatures resulted in lower contents of volatile materials and higher fixed carbon contents in the charcoal. Activation with heated water vapor positively influenced the adsorption of pigments from the $P$. guachapelle charcoal produced at $400{ }^{\circ} \mathrm{C}$ and the A. mangium and E. grandis charcoal produced at $500{ }^{\circ} \mathrm{C}$. The wood of $P$. guachapelle charred at $400{ }^{\circ} \mathrm{C}$ stood out in relation to the two other forest species analyzed.

Keywords: heated water vapor, adsorption of pigments in suspension, activated charcoal.
\end{abstract}

\section{INTRODUÇÃO}

O aumento da utilização de madeira oriunda de cultivos florestais, na sua grande maioria de espécies do gênero Eucalyptus, proporcionou uma pequena difusão de conhecimentos acerca do potencial energético de muitas espécies florestais. O pré-conhecimento de tais potencialidades poderia resultar no consorciamento com o eucalipto, amenizando os impactos provocados pela monocultura e, indiretamente, contribuindo para a diminuição da pressão sobre algumas espécies da flora brasileira (ANDRADE; CARVALHO, 1998; BARROS et al., 2012).

Apesar das espécies de Eucalyptus spp serem as mais utilizadas para produção de energia e de carvão vegetal, a Acacia mangium e Pseudosamanea guachapelle são espécies leguminosas exóticas apontadas com elevado potencial pela rusticidade, rapidez de crescimento e tolerância a solos marginais (VALE et al., 2000).

FLORESTA, Curitiba, PR, v. 47, n. 3, p. 323 - 332, jul. / set. 2017

Arruda, E. L. de et al.

ISSN eletrônico 1982-4688

DOI: $10.5380 /$ rf.v47i1.54063 
Além disso, são bastante indicadas para cultivos mistos e finalidades energéticas, já que as madeiras possuem características bem interessantes para as referidas utilizações (BARROS et al., 1990; VALE et al., 2000; DIAS et al., 2005).

No que se diz respeito à utilização de madeira para produção de carvão vegetal, a escolha da espécie é um fator que deve ser considerado no processo de carbonização, pois pode interferir na qualidade final do carvão, assim como na sua densidade, resistência mecânica, umidade, teor de carbono fixo, teores de cinzas e de materiais voláteis (OLIVEIRA et al., 2010; DIAS JÚNIOR et al., 2015). A temperatura final também é outro fator influenciável, pois age diretamente nas reações que ocorrem durante o processo de carbonização gerando produtos com características físicas e químicas bem diferentes (DERMIRBAS, 2004).

O carvão vegetal é um dos termoredutores mais importantes para a siderurgia nacional. Em 2015, a sua produção alcançou 6,6 milhões de toneladas, sendo quase a totalidade proveniente de florestas plantadas (BRASIL, 2016). Apesar do seu forte caráter siderúrgico, o carvão é comumente utilizado para a cocção de alimentos, produção de cimento, incorporação a substratos para produção de mudas entre outros. Adicionalmente, a ativação do carvão vegetal amplia as suas aplicações, a exemplo do que ocorre nas indústrias de açúcar para purificação e branqueamento; fabricação de óleos e gorduras; produção de bebidas alcoólicas, para a retirada de odores desagradáveis e adsorção de partículas em suspensão; purificação e armazenamento de produtos farmacêuticos; tratamento e descontaminação de água, eliminando odores, gostos desagradáveis e elementos tóxicos; purificação do ar, desodorização de ambientes e remoção de elementos metais pesados do solo (BANSAL; GOYAL, 2005; YU et al., 2006; MIMURA et al., 2010; KARUNAKARA et al., 2015; ILOMUANYA et al., 2017; WU et al., 2017).

Dentre os agentes de ativação do carvão destacam-se: o vapor d'água superaquecido, dióxido de carbono e outros gases oxidantes. Os métodos químicos, normalmente, utilizam como agentes de ativação o cloreto de zinco e sulfeto de potássio, sais desidratantes, ácido fosfórico, dolomita, hidróxido de sódio e ácido sulfúrico (ILOMUANYA et al., 2017; WU et al., 2017). Todavia, o método por vapor d'água é o mais barato e não limita as utilizações futuras do carvão vegetal ativado.

Com a ativação do carvão vegetal em vapor d'água superaquecido, os resíduos de hidrocarbonetos $\left(\mathrm{C}_{\mathrm{n}} \mathrm{H}_{\mathrm{m}}\right)$ podem ser dissolvidos e retirados da sua superfície por arraste ou liquefação. $\mathrm{O}$ mesmo fenômeno ocorre em relação ao alcatrão residual, que é solubilizado e, ou, arrastado pelo vapor d'água. A estrutura microcristalina do carvão é então formada durante a ativação e a sua porosidade torna-se bastante elevada. Pela ação do vapor ocorre o aumento da área superficial ativa, podendo chegar a valores da ordem de $2500 \mathrm{~m}^{2} \mathrm{~g}^{-1}$ (BRUM et al., 2008).

As propriedades de um carvão ativado são afetadas, principalmente, pela matéria-prima usada na sua produção e pelas condições de ativação. Com base nestes fatores, os carvões ativados podem apresentar propriedades de adsorção diferentes e servir para variados usos. Yu et al. (2006) abordaram a capacidade de adsorção de agentes herbicidas em solos com e sem a incorporação de carvão vegetal ativado produzido de diferentes espécies e temperaturas de carbonização. Os resultados obtidos pelos autores demonstraram melhores resultados para os solos que receberam o carvão vegetal produzido sob a maior temperatura final de carbonização, independente da espécie da madeira utilizada. Dessa forma, o desenvolvimento deste estudo teve como hipótese de que a elevação da temperatura de carbonização influencie positivamente nas propriedades da madeira carbonizada, assim como a ativação por vapor d'água superaquecido pode melhorar a capacidade de adsorção do carvão vegetal produzido.

Diante do exposto, os autores tiveram por objetivo analisar as variáveis da produção do carvão vegetal das madeiras de Acacia mangium, Pseudosamanea guachapelle e Eucalyptus grandis em três diferentes temperaturas e, avaliar a adsorção de pigmentos dissolvidos em água pelos carvões produzidos e ativados com vapor d'água superaquecido.

\section{MATERIAL E MÉTODOS}

\section{Obtenção e carbonização do material lenhoso}

As amostras das madeiras de Acacia mangium, Pseudosamaneae guachapelle e Eucalyptus grandis foram obtidas de cinco árvores de cada espécie, coletadas num experimento instalado no Campo Experimental da Embrapa Agrobiologia, no município de Seropédica, RJ. Na ocasião da colheita todas as árvores estavam com 15 anos de idade.

Após o abate, de cada árvore-amostra foram retirados seis discos de madeira, com aproximadamente três centímetros de espessura, para a realização das análises físico-químicas. Os discos foram retirados nas seguintes alturas do fuste, a partir do nível do solo: o primeiro a $0,30 \mathrm{~m}$, o segundo a $1,30 \mathrm{~m}$ (DAP) e os quatro restantes a $25 \%, 50 \%, 75 \%$ e $100 \%$ da altura total. Em seguida, o material foi acondicionado em embalagens 
plásticas e encaminhado para as análises subsequentes no Laboratório de Energia da Madeira do DPF/IF/UFRRJ.

Inicialmente determinou-se a densidade básica segundo a norma NBR 11941 (ABNT, 2003). Em seguida, as amostras dos materiais lenhosos foram cavaqueadas e secas até condição anidra em uma estufa a 103 $\pm 2{ }^{\circ} \mathrm{C}$. Dessa forma, o material absolutamente seco (a.s.) de cada espécie florestal foi carbonizado em forno elétrico tipo mufla, sob temperaturas máximas de 400,500 e $600{ }^{\circ} \mathrm{C}$, a uma taxa de aquecimento de $1,67{ }^{\circ} \mathrm{C} \mathrm{min}$ ${ }^{1}$ e com tempo total de 4,5 e 6 horas, respectivamente. A temperatura inicial foi de $100{ }^{\circ} \mathrm{C}$ e as amostras permaneceram durante 60 minutos na temperatura final estabelecida. Finalizado o processo, o forno mufla foi desligado para que atingissem a temperatura ambiente $\left(25^{\circ} \mathrm{C}\right)$ para a retirada dos carvões e análises subsequentes.

A tabela 1 apresenta o resumo dos tratamentos analisados.

Tabela 1. Tratamentos analisados.

Table 1. Treatments analyzed.

\begin{tabular}{|c|c|c|}
\hline Tratamento & Espécie florestal & Temperatura de carbonização \\
\hline $\mathrm{T} 1$ & & $400{ }^{\circ} \mathrm{C}$ \\
\hline $\mathrm{T} 2$ & $\begin{array}{c}\text { Acacia } \\
\text { (Acacia mangium) }\end{array}$ & $500{ }^{\circ} \mathrm{C}$ \\
\hline $\mathrm{T} 3$ & & $600^{\circ} \mathrm{C}$ \\
\hline $\mathrm{T} 4$ & & $400^{\circ} \mathrm{C}$ \\
\hline T5 & $\begin{array}{c}\text { Guachapelle } \\
\text { (Pseudosamaneae guachapelle) }\end{array}$ & $500{ }^{\circ} \mathrm{C}$ \\
\hline T6 & & $600^{\circ} \mathrm{C}$ \\
\hline $\mathrm{T} 7$ & & $400{ }^{\circ} \mathrm{C}$ \\
\hline $\mathrm{T} 8$ & $\begin{array}{c}\text { Eucalipto } \\
\text { (Eucalyptus grandis) }\end{array}$ & $500^{\circ} \mathrm{C}$ \\
\hline T9 & & $600{ }^{\circ} \mathrm{C}$ \\
\hline
\end{tabular}

Os vapores da carbonização foram condensados (líquido pirolenhoso), quantificados e armazenados. Os gases não condensáveis, com alguns constituintes inflamáveis na sua composição, foram queimados na saída do sistema de arrefecimento. De posse das massas de cada um dos produtos foram determinados os rendimentos gravimétricos em carvão (RCV), em líquido pirolenhoso (RLP) e em gases não condensáveis (RGNC).

\section{Caracterização do carvão vegetal}

Amostras representativas dos carvões produzidos foram separadas, maceradas e peneiradas. Posteriormente, foram realizadas as análises imediatas, utilizando-se alíquotas de $1 \mathrm{~g}$ e seguindo-se os procedimentos da norma D 1762-84 (ASTM, 1977), determinando-se os teores de materiais voláteis, de cinzas e de carbono fixo no carvão vegetal. A partir do produto do rendimento em carvão vegetal e do teor de carbono fixo obteve-se o rendimento em carbono fixo (RCF).

\section{Ativação dos carvões}

Para que não ocorresse perda de material, os carvões foram ativados entre duas peneiras de aço inoxidável (aberturas de 1,0 e 0,25 mm), sobrepostas e devidamente instaladas dentro de um recipiente com capacidade volumétrica de 12 litros. $\mathrm{O}$ vapor superaquecido de água $\left(300{ }^{\circ} \mathrm{C}\right)$, proveniente de um reator com pressão de $15 \mathrm{kgf} \mathrm{cm}^{-1}$, foi aplicado sobre as amostras dos carvões, através da tela de malha de 1,0 mm, durante quinze minutos. Após o tratamento em vapor d'água superaquecido os carvões foram secos a $103 \pm 2{ }^{\circ} \mathrm{C}$, até atingirem massa constante.

O processo de ativação dos carvões foi testado em meio aquoso, com base nas suas capacidades de adsorver micropartículas em suspensão seguindo as recomendações da norma ASTM E104-02 (ASTM, 2012). As soluções aquosas foram preparadas com 1,0\% de pigmento colorido, dissolvido em água deionizada. Utilizou-se para a pigmentação da água o corante em pó nas cores vermelho e verde, produzido pela Sherwin-

FLORESTA, Curitiba, PR, v. 47, n. 3, p. 323 - 332, jul. / set. 2017.

Arruda, E. L. de et al.

ISSN eletrônico 1982-4688

DOI: $10.5380 /$ rf.v47i1.54063 
Williams do Brasil Ltda, composto por dióxido de titânio, misturado com pigmentos orgânicos e inorgânicos. Foram comparadas as capacidades de adsorção dos carvões ativados e não ativados, em relação à massa inicial da amostra de carvão, dentro e entre cada temperatura de carbonização, para cada espécie florestal estudada, conforme os tratamentos estabelecidos (Tabela 1).

\section{Delineamento experimental e análise dos dados}

Procedeu-se a análise dos dados utilizando-se o delineamento experimental inteiramente aleatorizado (DIA), dentro de um esquema fatorial do tipo $3 \times 3 \times 2$ (espécies florestais x temperatura de carbonização $\mathrm{x}$ condição do carvão vegetal - ativado/não-ativado) com cinco repetições. Os dados obtidos foram submetidos ao teste de Kolmogorov-Smirnov para verificação da normalidade. Para verificar a homogeneidade das variâncias foi aplicado o teste de Levene, pois uma das hipóteses da análise de variância é que as variâncias sejam iguais para a categoria analisada. Verificadas essas suposições, foi realizada a análise de variância (ANAVA) e quando necessário, foi aplicado o teste de Tukey para comparação múltipla das médias.

A análise de regressão com base no teste $\mathrm{F}$ foi conduzida para as variáveis envolvendo a temperatura de carbonização e adsorção de pigmentos coloridos, aplicando-se posteriormente o teste $t$ para analisar individualmente o coeficiente de determinação. Quando necessário, os modelos foram ajustados para melhorar os valores do erro padrão e do coeficiente de determinação. Todos os testes foram conduzidos ao nível de 5\% de significância com auxílio do software Minitab $16^{\circledR}$.

\section{RESULTADOS}

A determinação da densidade básica teve como intuito caracterizar as madeiras das espécies estudadas. Dessa forma, os valores médios foram de $0,580 \mathrm{~g} \mathrm{~cm}^{-3}$ para a madeira de A. mangium, $0,560 \mathrm{~g} \mathrm{~cm}^{-3}$ para a $^{-}$ madeira de $P$. guachapelle e de $0,500 \mathrm{~g} \mathrm{~cm}^{-3}$ para a madeira de E. grandis.

Observa-se na tabela 2 que, os valores médios dos rendimentos gravimétricos em carvão diminuíram à medida que se elevou a temperatura máxima da carbonização, sendo o maior rendimento observado para a madeira de E. grandis, carbonizada a $400{ }^{\circ} \mathrm{C}(31,22 \%)$. Em seguida, aparecem os rendimentos das madeiras de A. mangium e $P$. guachapelle, carbonizadas na mesma temperatura, com valores de 30,54\% e 30,02\%, respectivamente.

Tabela 2. Rendimentos em carvão vegetal (RCV), em líquido pirolenhoso (RLP) e em gases não condensáveis (RGNC).

Table 2. Yields of charcoal (YC), pyroligneous liquid (PL) and non-condensable gases (NCG).

\begin{tabular}{cccccc}
\hline Tratamento & Espécie & Temperatura $\left({ }^{\circ} \mathbf{C}\right)$ & RCV $(\%)$ & RLP $(\%)$ & RGNC $(\%)$ \\
\hline T1 & 400 & $30,54 \pm 1,20$ & $39,21 \pm 1,01$ & $30,25 \pm 0,35$ \\
T2 & Acacia mangium & 500 & $27,91 \pm 1,30$ & $41,39 \pm 0,98$ & $30,70 \pm 0,42$ \\
T3 & & 600 & $27,07 \pm 1,48$ & $39,14 \pm 0,97$ & $33,79 \pm 0,39$ \\
\hline T4 & \multirow{2}{*}{ Pseudosamaneae } & 400 & $30,02 \pm 1,01$ & $38,15 \pm 0,78$ & $31,83 \pm 0,37$ \\
T5 & guachapelle & 500 & $27,87 \pm 1,21$ & $41,83 \pm 0,55$ & $30,30 \pm 0,37$ \\
T6 & 600 & $26,23 \pm 1,25$ & $41,88 \pm 0,65$ & $31,89 \pm 0,48$ \\
\hline T7 & & 400 & $31,22 \pm 1,65$ & $43,74 \pm 0,64$ & $25,04 \pm 0,55$ \\
T8 & Eucalyptus grandis & 500 & $28,78 \pm 1,66$ & $43,52 \pm 0,68$ & $27,70 \pm 0,48$ \\
T9 & & $27,33 \pm 1,88$ & $42,28 \pm 0,77$ & $30,39 \pm 0,59$ \\
\hline
\end{tabular}

Em que: Valores seguidos por $( \pm)=$ correspondem ao erro padrão da média.

Na temperatura de $500{ }^{\circ} \mathrm{C}$ não se observa grandes diferenças entre os rendimentos em carvão das espécies florestais analisadas e, a $600{ }^{\circ} \mathrm{C}$, sobressaíram-se as espécies E. grandis e A. mangium, cujos rendimentos médios em carvão foram de $27,33 \%$ e $27,07 \%$, respectivamente. Apesar da madeira de $P$. guachapelle ter apresentado um rendimento médio inferior, ele se mostrou bem próximo ao apresentado pela madeira de A. mangium $\left(500^{\circ} \mathrm{C}\right)$. Todas as espécies florestais apresentaram elevados rendimentos em carvão quando foram carbonizadas à temperatura de $400^{\circ} \mathrm{C}$.

Em relação aos rendimentos em líquido pirolenhoso e gases não condensáveis não foi detectada uma tendência bem definida, dentro e entre as espécies analisadas. Entretanto, de forma absoluta, a madeira de $E$. grandis, nas três temperaturas máximas de carbonização, apresentou rendimento em líquido pirolenhoso ligeiramente superior e rendimentos em gases não condensáveis inferiores, em comparação às madeiras das demais espécies.

Observa-se na tabela 3, para os carvões das três espécies florestais, que os teores de materiais voláteis 
diminuíram quando se elevou a temperatura de carbonização. Já para o teor de cinzas, os carvões da madeira de $P$. guachapelle apresentaram valores superiores àqueles apresentados pelas duas outras espécies florestais. Os teores de carbono fixo responderam positivamente ao aumento da temperatura de carbonização, enquanto que os rendimentos em carbono fixo praticamente se mantiveram estáveis, média de $23 \%$ para as espécies estudadas.

Tabela 3. Teores de materiais voláteis (TMV), de cinzas (TCZ), de carbono fixo (TCF) e rendimento em carbono fixo (RCF) dos carvões produzidos.

Table 3. Volatile matter (VM), ashes (AS), fixed carbon (FC) and fixed carbon yield (FCY) of the charcoal.

\begin{tabular}{|c|c|c|c|c|c|c|}
\hline Tratamento & Espécie & $\begin{array}{c}\text { Temperatura } \\
\left({ }^{\circ} \mathbf{C}\right)\end{array}$ & $\begin{array}{l}\text { TMV } \\
(\%)\end{array}$ & $\begin{array}{l}\text { TCZ } \\
(\%)\end{array}$ & $\begin{array}{l}\text { TCF } \\
(\%)\end{array}$ & $\begin{array}{l}\mathrm{RCF} \\
(\%)\end{array}$ \\
\hline $\mathrm{T} 1$ & \multirow{3}{*}{ Acacia mangium } & 400 & $24,50 \pm 2,33$ & $0,75 \pm 0,10$ & $74,75 \pm 4,12$ & $22,83 \pm 1,22$ \\
\hline $\mathrm{T} 2$ & & 500 & $12,00 \pm 2,01$ & $1,50 \pm 0,15$ & $86,50 \pm 4,22$ & $24,14 \pm 1,01$ \\
\hline $\mathrm{T} 3$ & & 600 & $8,75 \pm 1,99$ & $1,75 \pm 0,12$ & $89,50 \pm 3,02$ & $24,22 \pm 1,28$ \\
\hline $\mathrm{T} 4$ & \multirow{3}{*}{$\begin{array}{l}\text { Pseudosamaneae } \\
\text { guachapelle }\end{array}$} & 400 & $21,00 \pm 1,87$ & $4,50 \pm 1,01$ & $74,50 \pm 4,01$ & $22,36 \pm 1,87$ \\
\hline T5 & & 500 & $13,00 \pm 1,89$ & $4,00 \pm 1,12$ & $83,00 \pm 4,23$ & $23,13 \pm 1,54$ \\
\hline T6 & & 600 & $7,00 \pm 2,01$ & $4,00 \pm 1,13$ & $89,00 \pm 2,24$ & $23,34 \pm 1,23$ \\
\hline $\mathrm{T} 7$ & \multirow{3}{*}{ Eucalyptus grandis } & 400 & $23,75 \pm 2,22$ & $2,00 \pm 0,87$ & $74,25 \pm 3,03$ & $23,18 \pm 2,07$ \\
\hline $\mathrm{T} 8$ & & 500 & $11,25 \pm 1,33$ & $4,00 \pm 0,98$ & $84,75 \pm 3,12$ & $24,39 \pm 2,01$ \\
\hline T9 & & 600 & $6,75 \pm 1,37$ & $2,50 \pm 0,77$ & $90,75 \pm 2,97$ & $24,80 \pm 1,78$ \\
\hline
\end{tabular}

Em que: Valores seguidos por $( \pm)=$ correspondem ao erro padrão da média.

É possível observar que o carvão vegetal de cada espécie teve comportamento distinto em relação ao mecanismo de adsorção do pigmento para cada uma das temperaturas de carbonização (Tabela 4). Os carvões ativados das madeiras de acácia A. mangium e de E. grandis adsorveram maiores quantidades de pigmentos à medida que se aumentou a temperatura de carbonização. A mesma propriedade, no caso do carvão derivado da madeira de $P$. guachapelle, decresceu com o aumento da temperatura de carbonização. Já para o carvão vegetal não ativado, oriundo das madeiras das três espécies florestais, observa-se uma tendência da adsorção decrescer da temperatura de $400{ }^{\circ} \mathrm{C}$ para a de $500{ }^{\circ} \mathrm{C}$ e aumentar de $500{ }^{\circ} \mathrm{C}$ para $600{ }^{\circ} \mathrm{C}$. É possível que tal fato esteja relacionado ao aumento da densidade do carvão vegetal. Ela decresce até temperaturas próximas a $550{ }^{\circ} \mathrm{C}$, aumentando consideravelmente a partir desse patamar. Diante do aumento da densidade, o volume poroso diminui, e com ele a capacidade de adsorção relacionada à porosidade (DIAS JÚNIOR et al., 2016).

Tabela 4. Teores médios $(\%)$ de pigmentos adsorvidos em relação à massa inicial do carvão vegetal.

Table 4. Average contents (\%) of pigments adsorbed in relation to the original mass of the charcoal.

\begin{tabular}{|c|c|c|c|c|c|c|}
\hline \multirow{4}{*}{ Espécie } & \multicolumn{6}{|c|}{ Condição do carvão vegetal } \\
\hline & \multicolumn{3}{|c|}{ Ativado } & \multicolumn{3}{|c|}{ Não ativado } \\
\hline & \multicolumn{6}{|c|}{ Temperatura de carbonização } \\
\hline & $400{ }^{\circ} \mathrm{C}$ & $500{ }^{\circ} \mathrm{C}$ & $600{ }^{\circ} \mathrm{C}$ & $400^{\circ} \mathrm{C}$ & $500{ }^{\circ} \mathrm{C}$ & $600^{\circ} \mathrm{C}$ \\
\hline Acacia mangium & $0,42 \pm 0,02$ & $0,46 \pm 0,04$ & $0,82 \pm 0,05$ & $0,50 \pm 0,02$ & $0,33 \pm 0,01$ & $0,28 \pm 0,02$ \\
\hline $\begin{array}{l}\text { Pseudosamaneae } \\
\text { guachapelle }\end{array}$ & $1,02 \pm 0,05$ & $0,44 \pm 0,05$ & $0,64 \pm 0,06$ & $0,72 \pm 0,08$ & $0,44 \pm 0,03$ & $0,61 \pm 0,05$ \\
\hline $\begin{array}{l}\text { Eucalyptus } \\
\text { grandis }\end{array}$ & $0,45 \pm 0,02$ & $0,72 \pm 0,04$ & $0,71 \pm 0,08$ & $0,48 \pm 0,04$ & $0,41 \pm 0,03$ & $0,69 \pm 0,07$ \\
\hline
\end{tabular}

A figura 1 apresenta as amostras de carvão vegetal, durante e após a imersão em meio aquoso com os pigmentos coloridos, nos ensaios de adsorção. 

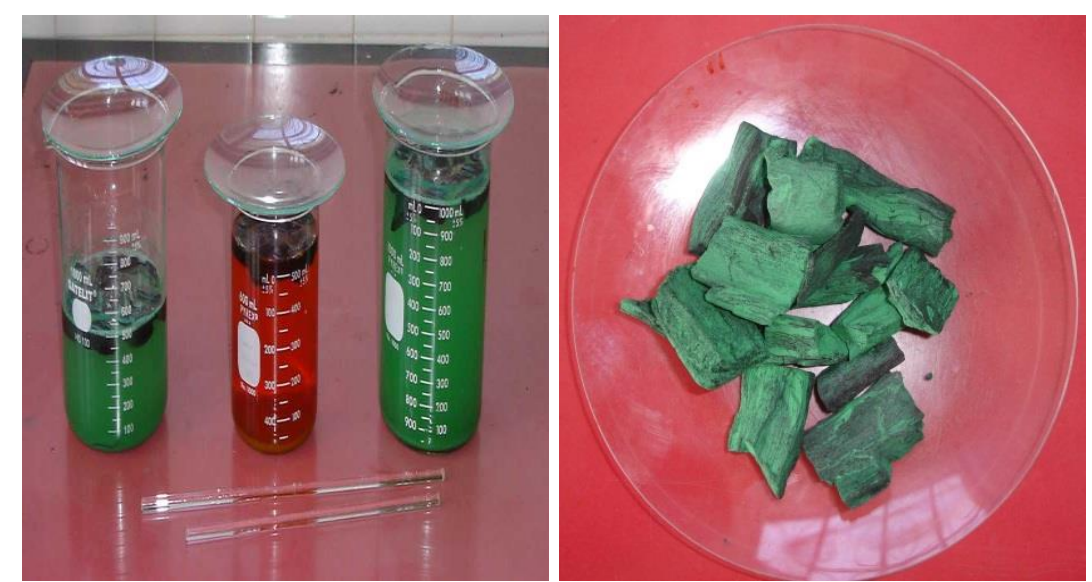

Figura 1. Resultados do ensaio de adsorção com carvão vegetal.

Figure 1. Results of adsorption test with charcoal.

Feita a análise do desdobramento da situação do carvão vegetal (ativado e não ativado), para cada espécie e temperatura de carbonização, em ordem crescente de adsorção, os carvões da A. mangium, seguidos pelos da $P$. guachapelle, apresentaram resultados positivos para a ativação. Os modelos ajustados (Figura 2) mostram ótimos coeficientes de determinação significativos para a probabilidade adotada. Essas observações relacionam à porosidade do carvão vegetal, característica associada a adsorção e resultantes das propriedades da madeira e das temperaturas de carbonização aplicadas (BROWN et al., 2006; YU et al., 2006; BERGERON et al., 2013; DIAS JÚNIOR et al., 2016).

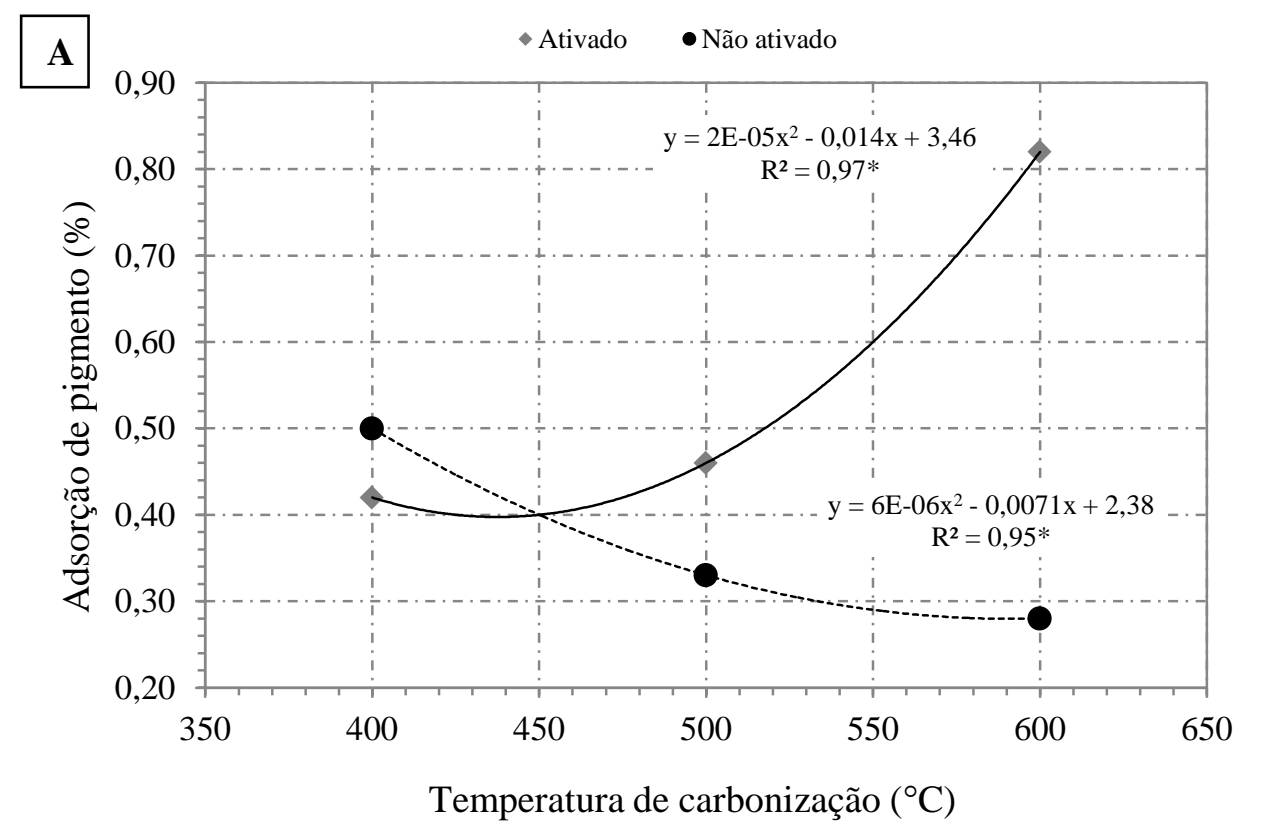




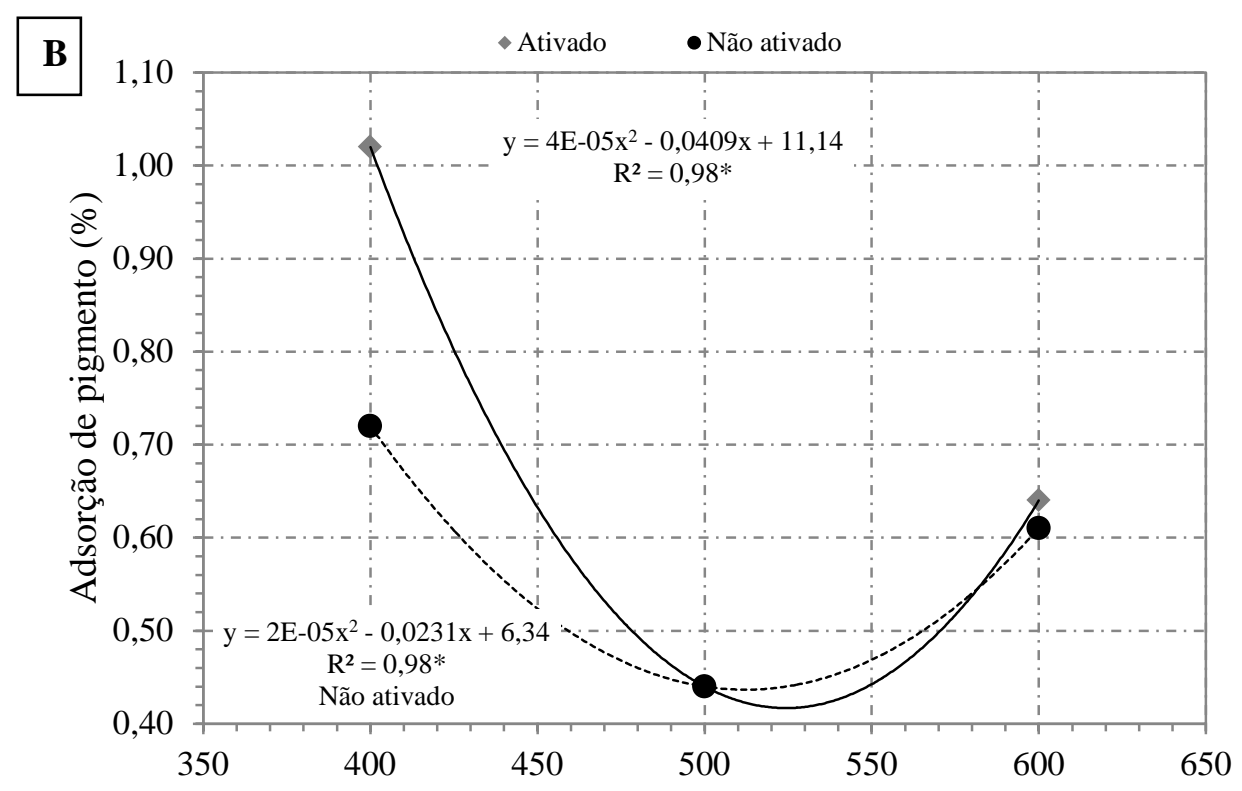

Temperatura de carbonização $\left({ }^{\circ} \mathrm{C}\right)$

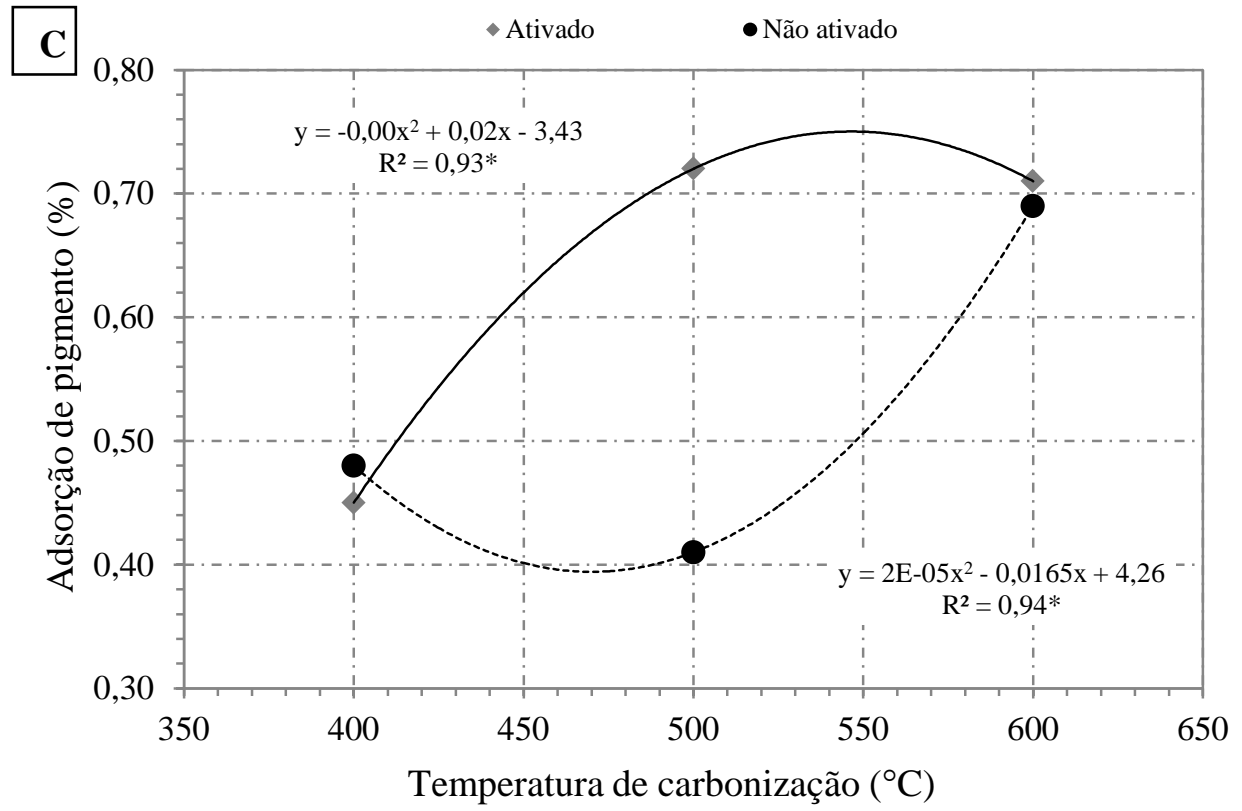

Figura 2. Modelos ajustados para o carvão vegetal de A. mangium (A), P. guachapelle (B) e E. grandis (C). *Significativos a $95 \%$ de probabilidade.

Figure 2. Mathematical models for the carbonization temperature and the pigment adsorption (\%) for charcoal of A. Mangium (A), P. guachapelle (B) e E. grandis (C). Significant at $95 \%$ probability.

\section{DISCUSSÃO}

Para a densidade básica, os valores obtidos são considerados satisfatórios para utilizações energéticas: lenha e carvão vegetal (DIAS JÚNIOR et al., 2015). Segundo Oliveira et al. (2010), para a produção de carvão, a madeira deve apresentar uma densidade básica média próxima a $0,520 \mathrm{~g} \mathrm{~cm}^{-3}$. Com base nisso, os resultados observados nesta pesquisa indicam que as matérias primas analisadas apresentam potencial para as referidas utilizações.

É possível que o aumento da temperatura eleve a quantidade de gases formados (condensáveis e não condensáveis) e que, dentre os condensáveis, são os vapores mais voláteis que colaboram para elevar a quantidade de líquido pirolenhoso (KELYOUNSSI; HALIM, 2014). Como o rendimento em gases não

FLORESTA, Curitiba, PR, v. 47, n. 3, p. 323 - 332, jul. / set. 2017

Arruda, E. L. de et al.

ISSN eletrônico 1982-4688

DOI: $10.5380 /$ rf.v47i1.54063 
condensáveis (RGNC) é calculado com base nos rendimentos em carvão (RCV) e líquido pirolenhoso (RLP), observa-se elevadas médias de RGNC para as carbonizações conduzidas sob maiores temperaturas finais. Temperaturas mais altas agem de uma forma mais intensa sobre o material carbonizado, proporcionando uma maior liberação de gases (DEMIRBAS, 2004). Essa afirmação pode ser comprovada, ao se observar que houve uma tendência de que os valores inferiores de rendimento em carvão, assim como os valores superiores de rendimentos em líquido pirolenhoso e em gases não condensáveis, tenham sido observados nas carbonizações conduzidas à temperatura de $600{ }^{\circ} \mathrm{C}$.

A análise imediata dos carvões demonstrou, para as três espécies florestais analisadas, que ocorre a diminuição dos teores de materiais voláteis (TMV) à medida que se eleva a temperatura de carbonização. Os menores TMV decorreram de uma maior eliminação dos mesmos nas temperaturas de carbonização mais elevadas (DIAS JÚNIOR et al., 2016). O contrário foi observado em relação aos teores de carbono fixo (TCF) dos carvões, ou seja, quanto maior a temperatura de carbonização, maior o TCF nos carvões. O incremento do teor de carbono no carvão em resposta ao aumento da temperatura final de carbonização também é citado por Demirbas (2004) e Vieira et al. (2013). Para uma mesma espécie, há uma tendência em aumentar o teor de cinzas à medida que se diminui o rendimento gravimétrico em carvão.

Os rendimentos em carbono fixo (RCF) apresentaram valores médios distribuídos num intervalo de $22,36 \%$ a 24,80\%. Esta variável é um dos parâmetros que melhor expressam a qualidade da matéria prima lenhosa para a produção de carvão vegetal (DEMIRBAS, 2004). Quanto maior for o RCF, melhor será a qualidade da biomassa para fins energéticos. Ele, oriundo da madeira de Eucalyptus spp, geralmente, situa-se em torno dos $27 \%$, ou seja, valor mais elevado do que a média observada no presente estudo, independente da temperatura de carbonização. Tal fato, decorre da relação inversamente proporcional entre o rendimento em carvão vegetal e o teor de carbono fixo (DIAS JÚNIOR et al., 2016). Em termos absolutos, o maior RCF foi apresentado pela madeira de E. grandis, carbonizada a $600{ }^{\circ} \mathrm{C}$.

Observa-se que ativação por vapor d'água superaquecido aumentou a capacidade de adsorção de pigmentos coloridos pelos carvões de A. mangium produzidos a 500 e $600{ }^{\circ} \mathrm{C}$. Para o carvão vegetal derivado da madeira de $P$. guachapelle, a ativação surtiu efeito nos carvões produzidos à $400{ }^{\circ} \mathrm{C}$. Estes carvões podem ser recomendados utilização na descoloração e filtragem de água e/ou de bebidas, uma vez que as suas propriedades de adsorção foram significativamente intensificadas pela ativação (Figura 2A e Figura 2B) (BANSAL; GOYAL, 2005).

Os resultados comprovam os efeitos positivos da ativação utilizando-se o vapor superaquecido, uma vez que foi notada a elevação da capacidade de adsorção dos carvões produzidos. Tendo por base as propriedades dos carvões ativados é possível recomendar a adoção dos mesmos, dentre outros usos, para a filtragem, purificação e descoloração de água e, ou, bebidas. No entanto, é preciso considerar que as propriedades dos materiais adsorvidos (dimensão da molécula, massa molecular, polaridade, etc.) e as propriedades da superfície do adsorvente (polaridade, estrutura e distribuição dos poros, área superficial, etc.) determinam a intensidade da interação (BANSAL; GOYAL, 2005).

As variáveis analisadas no carvão vegetal não ativado, não apresentaram diferenças significativas em nenhum dos tratamentos, ou seja, as espécies e temperaturas de carbonização não tiveram influência sobre as curvas de adsorção. Analisando os materiais ativados, considerando-se as temperaturas e as espécies vegetais, percebe-se que a madeira de $P$. guachapelle, carbonizada à temperatura máxima de $400{ }^{\circ} \mathrm{C}$, se destaca em relação às duas outras espécies florestais analisadas.

Neste estudo, a capacidade de adsorção do carvão vegetal foi incrementada pelo processo de ativação (Figura 1). Como resultante, houve maiores valores para a retenção de pigmentos. A desobstrução dos poros e o aumento da porosidade são os possíveis fatores que colaboraram para a melhoria das propriedades de adsorção do carvão vegetal, facilitando a retenção dos pigmentos (BERGERON et al., 2013; KELYOUNSSI; HALIM, 2014). Além disso, mesmo que a porosidade seja parecida, a distribuição dimensional dos poros tem sido utilizada para descrever a capacidade de adsorção. Os microporos são os detentores de alto poder capilar e surgem em carvões produzidos sob elevadas temperaturas ou que sofreram algum tipo de ativação (YU et al., 2006; ILOMUANYA et al., 2017).

De forma geral, as três espécies florestais apresentaram resultados que viabilizam a utilização para a produção de carvão vegetal e, o processo de ativação pela ação do vapor d'água superaquecido se mostrou satisfatório, pois proporcionou aumentos significativos na capacidade de adsorção de pigmentos dissolvidos em solução aquosa pelos carvões ativados. 


\section{CONCLUSÕES}

- Os maiores rendimentos em carvão vegetal são observados para a carbonização conduzida de $400{ }^{\circ} \mathrm{C}$, para as três espécies florestais estudadas (E. grandis, P. guachapelle e A. mangium).

- A ativação com vapor d'água superaquecido influencia positivamente a adsorção de pigmentos do carvão de P. guachapelle produzido a $400{ }^{\circ} \mathrm{C}$ e dos carvões de A. mangium e E. grandis produzidos a $500{ }^{\circ} \mathrm{C}$.

- A madeira de $P$. guachapelle carbonizada à $400{ }^{\circ} \mathrm{C}$ se destacou em relação às duas outras espécies florestais analisadas.

\section{REFERÊNCIAS}

ANDRADE, A. M. de; CARVALHO, L. M. de. Potencialidades energéticas de oito espécies florestais do Estado do Rio de Janeiro. Floresta e Ambiente, Seropédica, v. 5, n. 1, p. 24-42, 1998.

AMERICAN SOCIETY FOR TESTING AND MATERIALS (ASTM). ASTM D 1762-84: Standard method for chemical analyses of wood charcoal. Phyladelphia: 1977. 1042p.

ASTM E104-02: Standard practice for maintaining constant relative humity by means of aqueous solutions. Philadelphia: 2012. 5p.

ASSOCIAÇÃO BRASILEIRA DE NORMAS TÉCNICAS (ABNT). NBR 11941: Madeira - Determinação da densidade básica. Rio de Janeiro: 2003. 6p.

BANSAL, R. C.; GOYAL, M. Activated carbon adsorption. Boca Raton: Taylor e Francis, 1 ed. 2005, 98p.

BARROS, N. F.; NOVAES, R. F.; NEVES, J. C. L. Fertilização e correção do solo para o plantio de Eucalipto. Viçosa: Ed. Folha de Viçosa, 1 ed. 1990. 186p.

BARROS, S. V. S.; NASCIMENTO, C. C.; AZEVEDO, C. P. Caracterização tecnológica da madeira de três espécies florestais cultivadas no amazonas: alternativa para produção de lenha. Floresta, Curitiba, v. 42, n. 4, p. 725-733, 2012.

BERGERON, S. P.; BRADLEY, R. L; MUNSON, A.; PARSONS, W. Physico-chemical and functional characteristics of soil charcoal produced at five different temperatures. Soil Biology \& Biochemistry, Amesterdã, v. 58, p. 140-146, 2013.

BRASIL - BALANÇO ENERGÉTICO NACIONAL (BEN). Relatório anual (ano base 2015). Brasília: Empresa de Pesquisa Energética. 2016. 291 p. Disponível em: <https://ben.epe.gov.br/downloads/Relatorio_ Final_BEN_2015.pdf>. Acesso em: 24/05/2017.

BROWN, R. A.; KERCHER, A. K.; NGUYEN, T. H.; NAGLE, D. C.; BALL, W. P. Production and characterization of synthetic wood chars for use as surrogates for natural sorbents. Organic Geochemistry, Amesterdã, n. 3, v. 37, p. 321-333, 2006.

BRUM, S. S.; BIANCHI, M. L.; SILVA, V. L.; GONÇALVES, M.; GUERREIRO, M. C. G.; OLIVEIRA, L. C. A. Preparação e caracterização de carvão ativado produzido a partir de resíduos do beneficiamento do café. Química Nova, São Paulo, v. 31, n. 5, p. 1048-1052, 2008.

DERMIRBAS, A. Relationships between carbonization temperature and pyrolysis products from biomass. Energy Exploration \& Exploitation, Amesterdã, v. 22, n. 6, p. 411-420, 2004.

DIAS, P. F.; SOUTO, M.; CHAER, G. M.; CARNEIRO, E. F.; SOUZA, A. C.; JIMENEZ, L.; FRANCO, A. A. Avaliação de leguminosas arbóreas introduzidas em pastagens da baixada e região Serrana do Estado do Rio de Janeiro. Pasturas Tropicales, Rio de Janeiro, v. 28, n. 1, 2005.

DIAS JÚNIOR, A. F.; ANDRADE, A. M. de; WERNECK, V. S.; COSTA JÚNIOR, D. S.; FERREIRA, D. A. A.; LELES, P. S. S. Potencial energético de sete materiais genéticos de Eucalyptus cultivados no Estado do Rio de Janeiro. Scientia Forestalis, Piracicaba, v. 4, n. 108, p. 478-485, 2015.

DIAS JÚNIOR, A. F.; PIROLA, L. P.; TAKESHYTA, S.; LANA, A. Q.; BRITO, J. O.; ANDRADE, A. M. Higroscopicity of charcoal produced in different temperatures. Cerne, Lavras, v. 22, n. 4, p. 423-430, 2016.

ILOMUANYA, M. O.; NASHIRU, B.; IFUDU, N. D.; IGWILO, C. I. Effect of pore size and morphology of activated charcoal prepared from midribs of Elaeis guineensis on adsorption of poisons using metronidazole and

FLORESTA, Curitiba, PR, v. 47, n. 3, p. 323 - 332, jul. / set. 2017.

Arruda, E. L. de et al.

ISSN eletrônico 1982-4688

DOI: $10.5380 /$ rf.v47i1.54063 
Escherichia coli O157:H7 as a case study. Journal of Microscopy and Ultrastructure, Tokyo, v. 3, n. 45, p. 345-352, 2017.

KARUNAKARA, N.; KUMARA, K. S.; YASHODHARA, I.; SAHOO, B. K.; GAWARE, J. J.; SAPRA, B. K.; MAYYA, Y. S. Evaluation of radon adsorption characteristics of a coconut shell-based activated system for radon and thoron removal applications. Journal of Environmental Radioactivity, Amesterdã, v. 142, p. 87-95, 2015 .

KELYOUNSSI, K.; HALIM, M. An investigation on the texture and microstructure of carbonized charcoals produced by two-step pyrolysis. Journal of Analytical and Applied Pyrolysis, Amesterdã, v. 3, n. 109, p. 258265, 2014.

MIMURA, A. M. S.; SALES, J. R. C.; PINHEIRO, P. C. Atividades experimentais simples envolvendo adsorção sobre carvão. Química Nova na Escola, São Paulo, v. 32, n. 1, p. 1-2, 2010.

OLIVEIRA, A. C.; CARNEIRO, A. de C. O.; VITAL, B. R.; ALMEIDA, W.; PEREIRA, B. L. C.; CARDOSO, M. T. Parâmetros de qualidade da madeira e do carvão vegetal de Eucalyptus pellita F. Muell. Scientia Forestalis, Piracicaba, v. 38, n. 87, p. 431-439, 2010.

SOMERVILLE, M.; JAHANSHAHI, S. The effect of temperature and compression during pyrolysis on the density of charcoal made from Australian eucalypt wood. Renewable Energy, Amesterdã, v. 80, p. 471-478, 2015.

VAlE, A. T.; BRASIL, M. A. M.; CARVAlhO, C. M.; VEIGA, R. A. A. Produção de energia do fuste de Eucalyptus grandis Hill Ex-Maiden e Acacia mangium Willd em diferentes níveis de adubação. Cerne, Lavras, v. 6, n. 1, p. $83-88,2000$.

VIEIRA, R. S.; LiMA, J. T.; MONTEIRO, T. C.; SElVATTI, T. S.; BARAÚNA, E. E. P.; NAPOLI, A. Influência da temperatura no rendimento dos produtos da carbonização de Eucalyptus microcorys. Cerne, Lavras, v. 19, n. 1, p. 59-64, 2013.

WU, Y. MING, Z.; YANG, S.; FAN, Y.; FANG, P.; SHA, H.; CHA, L. Adsorption of hexavalent chromium onto Bamboo Charcoal grafted by $\mathrm{Cu}^{2+}-\mathrm{N}$-aminopropylsilane complexes: Optimization, kinetic, and isotherm studies. Journal of Industrial and Engineering Chemistry, Amesterdã, v. 42, p. 212-220, 2017.

YU, X. Y.; YING, G. G.; KOOKANA, R. S. Sorption and desorption behaviors of diuron in soils amended with charcoal. Journal Agriculture and Food Chemistry, Washington, v. 54, p. 8545-8550, 2006. 